\title{
An interstitial deletion of chromosome 7(q35)
}

\author{
Kerry Fagan, Christine Kennedy, Laurence Roddick, Alison Colley
}

\begin{abstract}
We describe a patient with developmental delay, mild dysmorphic features, and monosomy of 7 q35. Only one other patient with an interstitial deletion of this band has been previously reported. A review of clinical features of these two children did not show similarities in dysmorphic features. Reports of patients with other $7 q$ interstitial deletions are listed.
\end{abstract}

(f Med Genet 1994;31:738-739)

Interstitial deletions resulting in partial monosomy for different segments of the long arm of chromosome 7 have been described in cytogenetic publications. ${ }^{12}$ These case reports have been broadly classified according to the deleted segment into three main groups: deletions of 7(q11), del(7)(q21), and $\operatorname{del}(7)(\mathrm{q} 31)$. Fewer cases have been reported with deletions of 7(q33) and 7(q34). The phenotypic features of our patient with deletion of band q35 are presented and other patients with deletions involving the $7(\mathrm{q} 3)$ region are reviewed.

\section{Case report}

The proband was the second child of nonconsanguineous parents. Her mother was 28 years and her father 33 years at the time of her birth. Her mother had two first trimester spontaneous abortions and has two normal sons. Labour was induced at 42 weeks of gestation after an uncomplicated pregnancy; birth weight was $2970 \mathrm{~g}$ and length was $49.5 \mathrm{~cm}$. There was neonatal jaundice owing to $\mathrm{Rh}$ incompatibility with no major complications. Physical milestones were within normal limits; she sat by 7 months, crawled by 8 months, and walked by 14 months, but used only a single word until aged $2 \frac{1}{2}$ years. At $3 \frac{1}{2}$ years she still had only a few single words and speech therapy, which included Makaton signing, was started. Apart from bilateral hypermetropia and a convergent squint, her general health was good.

From the age of 2 years the proband attended special education and language classes. At $4 \cdot 4$ years the Reynell verbal comprehension scale put her expressive language at only 2.4 years. At 7 years a WPPSI assessment gave a full scale of 85 and at the age of 10 years a Stanford Binet assessment showed her to be functioning in the mildly intellectually handicapped range.

Biochemical studies including thyroid function tests, mucopolysaccharide screen, and urinary amino and organic acids were all normal, as was her cerebral CT scan. Bone age was appropriate to chronological age.

When reviewed at the age of 11 years her head circumference was on the 50th centile with height and weight between the 90th and 95th centiles. Dysmorphic features included epicanthic folds and almond shaped eyes (fig 1). Her inner and outer canthal distances and interpupillary distance were all on the 50th centile. There was a marked left convergent squint, a high palate, and a bulbous nasal tip. She had low set, posteriorly rotated ears and apparent micrognathia. Her speech was markedly hypernasal; her palate and uvula appeared normal; however, velopharyngeal incompetence was shown on video fluoroscopy. She attends special classes in a normal school.

\section{CYTOGENETIC STUDIES}

Chromosome studies performed on the patient at birth and at the age of 2 years showed an apparently normal female karyotype. On reexamination at 11 years using high resolution cytogenetic techniques, a small interstitial deletion of band q35 was detectable on one chromosome 7 (fig 2). This constitutes a loss of only $0 \cdot 18 \%$ of HAL (haploid autosome length). The karyotype can be described as: 46,XX, $\operatorname{del}(7)$ (pter $\rightarrow \mathrm{q} 34:: \mathrm{q} 36 \rightarrow \mathrm{qter})$. The chromosomes, painted with a chromosome 7 specific probe (Cambio) by fluorescent in situ hybridisation, did not show evidence of a cryptic translocation or insertion. The parental chromosomes were normal

\section{Discussion}

Deletions of interstitial segments of the long arm of chromosome 7 are still relatively rare. A review of published reports indicates several broad groups of $7 \mathrm{q}$ deletions which have breakpoints and phenotypic features in common (fig 3).

A deletion which includes the $G$ band negative region of q11 results in severe growth and developmental retardation and a poor prognosis. ${ }^{1}$ Spasms and seizures are common and most patients remain non-ambulatory.

Four patients with interstitial deletions of chromosome 7 which included loss of band q21 have been reported. ${ }^{12}$ These patients all had split hand/split foot malformations among other dysmorphic features.

The most common interstitial deletion reported for chromosome $7, \operatorname{del}(7)(\mathrm{q} 22 \rightarrow 31)$, has been described in 12 patients ${ }^{1}$ so far and a characteristic clinical picture is now emerging, including severe developmental retardation, an unusual cry in infancy, a large mouth, seizures, and feeding or gastro-oesophageal difficulties.

Patients with interstitial deletions in the q3 region of chromosome 7 include three members of one family with monosomy for bands
Received 11 February 1994 Revised version accepted for publication 8 April 1994 

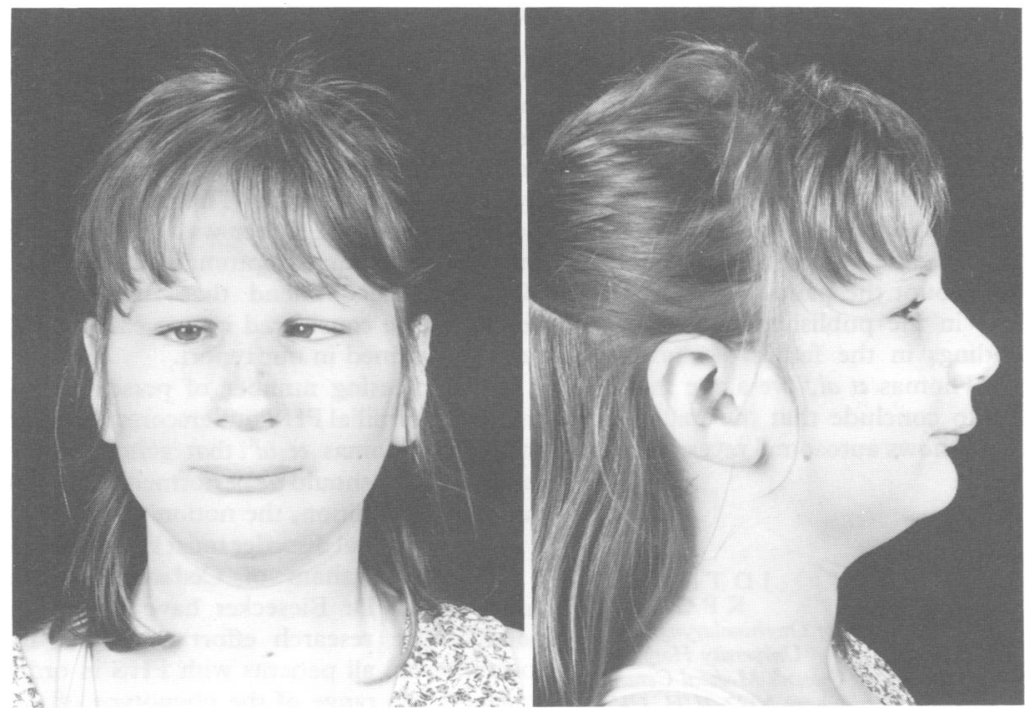

Figure 1 Facial appearance at 11 years.
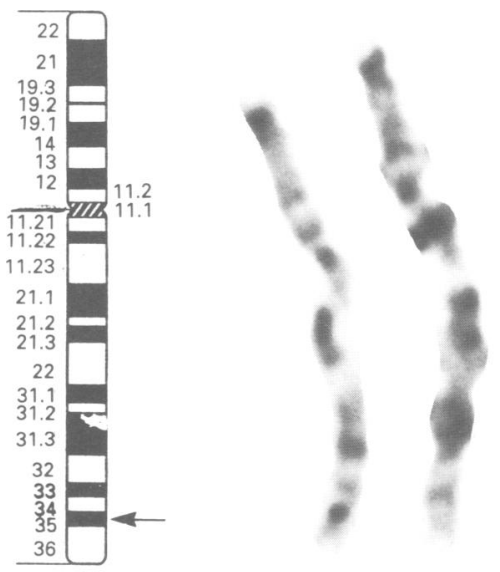

7

Figure $2 G$ banded partial karyotype. Deleted chromosome 7 is on the right.

p

$\mathbf{q}$

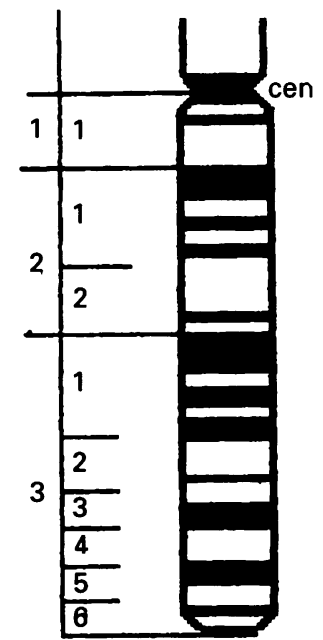

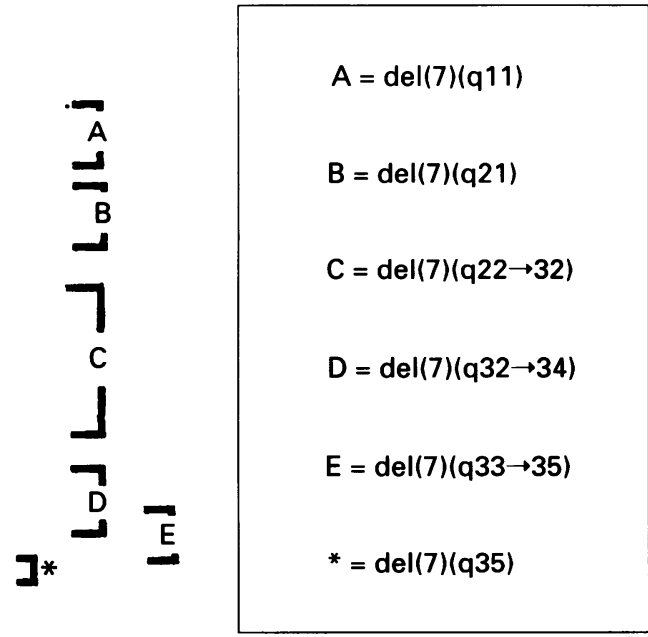

$\mathrm{q} 32 \rightarrow 34 .^{3}$ Their deletion resulted from malsegregation of an inversion carrier and the patients all had similar phenotypic features, including mental and developmental retardation, external ear malformation, hypertelorism, flat nasal bridge, a bulbous nose tip, and a wide mouth. A single case report of a deletion of bands q33 and q34 4 (patient 3 ) had microcephaly, prominent forehead, mongoloid slant of the eyes, bilateral simian creases, and clitoralmegaly, as well as severe growth and developmental retardation. One patient described $^{5}$ had a deletion of bands $7 \mathrm{q} 33 \rightarrow \mathrm{q} 35$. Her features included microcephaly, neurodevelopmental delay, a cleft lip and palate, conductive deafness, and protruding tongue.

One patient has monosomy for band $7 \mathrm{q} 35$, similar to our patient, but it resulted from a de novo translocation $\mathrm{t}(3 ; 7)$ (q27; $\mathrm{q} 35) .^{2}$ This patient was severely hypotonic at birth with absent Moro reflex; she had microbrachycephaly, ptosis of the left eyelid, alternate squint, small nose with a flat nasal bridge, and microstomia. The growth rate had been below the 3 rd centile. Seizures occurred shortly after birth and a profound neural hearing deficit was documented. By comparison, our patient shows only mild dysmorphism but has a squint in common with their patient.

\section{Conclusions}

The clinical features of patients described with interstitial deletions of different segments of the long arm of chromosome 7 vary. More case reports are needed with deletion breakpoints accurately defined using high resolution banding to confirm whether a pattern of phenotypic characteristics can be described. Our case reiterates the need to repeat testing when a chromosome anomaly is suspected, despite an initially normal karyotype.

EBV transformation of the patient's lymphocytes is in process and will be available on request.

1 Fagan K, Gill A, Henry R, Wilkinson I, Cary W. A summary of $7 \mathrm{q}$ interstitial deletions and exclusion mapping of th gene for $\beta$-glucuronidase. 7 Med Genet 1989;26:619-25.

2 Fryns JP, Kleczkowska A, Van den Berghe $\mathrm{H}$. De novo $3 \mathrm{q}$ $7 \mathrm{q}$ translocation and associated interstitial $7 \mathrm{q} 35$ deletion Clin Genet 1988;33:60-2.

3 Nielsen KB, Egede F, Mouridsen I, Mohr J. Familial partial $7 \mathrm{q}$ monosomy resulting from segregation of an insertional chromosome rearrangement. F Med Genet 1979;16:461-6.

4 Bateman MA, Philip N, Mattei MG, Mattei JF. Clinical, chromosomal and enzymatic studies in four cases of rearrangements of chromosome 7. Clin Genet 1985;27:564-9.

5 Verma RS, Conte RA, Sayegh SE, Kanjilal D. The interstitial deletion of bands q33-35 of long arm of chromosome 7 a review with a new case report. Clin Genet 1992;42:82-6.

Figure 3 Diagram of $7 q$ interstitial deletions in reported cases. 